\title{
"MYH9 mutation and squamous cell cancer of the tongue in a young adult: a novel case report"
}

Takako Eva Yabe ${ }^{1,2^{*}}$ (D), Kylie King ${ }^{3}$, Susan Russell ${ }^{4,5}$, Laveniya Satgunaseelan ${ }^{6,7}$ (D), Ruta Gupta ${ }^{6,7}$ (D), James Chen $^{8}$ and Bruce Ashford ${ }^{1,2,9}$ (i)

\begin{abstract}
Background: The incidence of tongue cancer in young adults is on the rise. This trend is more pronounced in females. Although the aetiology is still unclear, there is mounting evidence that genetic syndromes can play a key role in development of oral cancers in this patient group. We report the first case of oral squamous cell carcinoma (OSCC) in a young adult with an MYH9-related disorder (MYH9-RD).

Case presentation: A 19-year-old female with a germline MYH9 variant (missense variant in exon 2: C.287C > T, (p.Ser96Leu)) was referred to the head and neck surgery department for investigation of a painful, thick right tongue ulcer. She was diagnosed with Epstein syndrome, an MYH9-RD, at 12 years of age. Her main phenotypic features were profound thrombocytopenia and marked renal impairment. The tongue biopsy confirmed SCC. Preoperative positron emission tomography (PET) revealed avidity in the right tongue and ipsilateral level 2A neck lymph node. With substantial preoperative multidisciplinary input, she underwent cancer ablation and microvascular free flap reconstruction. Her pathology showed a $35 \mathrm{~mm}$ diameter, $14 \mathrm{~mm}$ thick moderately differentiated SCC with perineural and lymphovascular invasion. Two out of 38 right neck nodes were positive for metastasis with extranodal extension. None of the 34 left neck nodes was involved.

She had an uneventful recovery and was discharged home on day 6 postoperative day. On day 15 postoperative day, she had catastrophic bleeding in the neck with a respiratory arrest after a forceful cough. She required an emergency tracheostomy and returned to the theatre for haemostasis. Following a short inpatient stay, she was again discharged home and underwent adjuvant therapy consisting of external beam radiotherapy of 60Gy in 30 fractions. On clinical examination and PET at 6 months after surgery, she had no evidence of disease recurrence.
\end{abstract}

Conclusions: MYH9-RD can present with advanced locoregional oral cavity malignancy at an early age. The combination of profound thrombocytopenia and marked renal impairment can impact heavily on routine major head and neck cancer surgery and adjuvant treatment. This rare and challenging condition underlines the importance of early detection of cancer and multidisciplinary team input.

Keywords: Squamous cell carcinoma, Tongue, Young adult, MYH9, Epstein syndrome, Neck dissection, Free flap, Microvascular surgery

\footnotetext{
* Correspondence: Takako.Yabe@health.nsw.gov.au

'Department of Head and Neck Surgery, Wollongong Hospital, Wollongong, NSW, Australia

${ }^{2}$ Illawarra Health and Medical Research Institute, Wollongong, NSW, Australia

Full list of author information is available at the end of the article
}

\section{$\triangle B M C$}

(c) The Author(s). 2022 Open Access This article is licensed under a Creative Commons Attribution 4.0 International License, which permits use, sharing, adaptation, distribution and reproduction in any medium or format, as long as you give appropriate credit to the original author(s) and the source, provide a link to the Creative Commons licence, and indicate if changes were made. The images or other third party material in this article are included in the article's Creative Commons licence, unless indicated otherwise in a credit line to the material. If material is not included in the article's Creative Commons licence and your intended use is not permitted by statutory regulation or exceeds the permitted use, you will need to obtain permission directly from the copyright holder. To view a copy of this licence, visit http://creativecommons.org/licenses/by/4.0/. The Creative Commons Public Domain Dedication waiver (http://creativecommons.org/publicdomain/zero/1.0/) applies to the data made available in this article, unless otherwise stated in a credit line to the data. 


\section{Background}

An international multi-institutional analysis by Satgunaseelan et al. [1] demonstrated that the incidence of tongue cancer is rising faster in younger patients $(\leq 45$ years of age) compared to older patients ( $>45$ years of age). In the younger cohort, the incidence increased at significantly higher rate in females, compared to male ( $4.3 \%$ vs $1.5 \%$ per year). There are certain genetic syndromes such as Fanconi anaemia [2] and dyskeratosis congenita [3], which are known to be linked to oral cancers at an early age. To date, there is no report of a tongue cancer in a young adult with Myosin Heavy Chain 9 (MYH9) mutation.

The MYH9 gene encodes the non-muscular myosin heavy chain IIA (NMHCIIA), a cytoskeletal contractile protein. The NMHCIIAs are expressed in all eukaryotic cells [4]. MYH9 mutation may result in thrombocytopaenia and platelet macrocytosis, sensorineural deafness, cataracts and/or renal impairment. These rare autosomal dominant disorders are known as MYH9-related disorders (MYH9-RDs), and encompass May-Hegglin anomaly, Sebastian, Fechtner, and Epstein syndromes [5]. MYH9-RDs are rare, and only 113 unrelated families are reported in the literature [6]. Based on the Exome Aggregation Consortium (ExAC) database, prevalence is approximately 1:20,000 - 25,000 [7]. The expression of clinical features is heterogenous [8]. In some individuals, the haematological features remain the only manifestations of the disorder throughout life. It is thought that approximately $35 \%$ of index cases are sporadic $[9,10]$. In more than half of these cases, a de novo mutation was confirmed by segregation analysis.

Besides the motorised protein impacts, differential expression of $M Y H 9$ has been implicated in cancer invasion and metastasis [11-14]. MYH9 can act both as an oncogene and a tumour suppressor in different cancers; however, in the context of head and neck cancers, MYH9 has been shown to have synergistic influence on cell invasion with TP53 [15]. TP53 is the most frequently mutated gene in head and neck squamous cell carcinoma (HNSCC), occurring in more than $70 \%$ of cases of non-human papillomavirus (HPV) SCC [16-18]. Most high impact alterations involving tumour suppressor genes render them non-functional through truncation or deletion [15]. However, TP53 is unique because there is a strong propensity for missense mutations, particularly within its DNA-binding domain. MYH9 mutations have been shown to impair an in vitro p53 response to DNA damage, with the majority of MYH9 mutations clustering in the ATPase domain [13]. This tumour suppressive role of $M Y H 9$ is enacted through NMHCIIA [15]. Cell line studies have shown that inhibition of NMHCIIA prevents the nuclear localisation of p53, crucial for downstream tumour suppressive functions [13, 15, 19-
21]. The tumour suppressor capability of p53 is therefore dependent on NMHCIIA function in head and neck cancer. Inhibition of NMHCIIA leads to increased invasion in wildtype (wt)p53 expressing cells but not in high-risk mutated (mut)p53 expressing cells [15]. These findings indicate that cells with a wtp53 phenotype are dependent on NMHCIIA inhibition for invasive capability, secondary to decreased nuclear accumulation of wtp53, and subsequent reduction in target gene expression. In contrast, cells harbouring high-risk mutp53 attain an invasive phenotype independent of NMHCIIA expression [17].

MYH9 is a well-conserved gene through evolution from fungi to mammals. The similarity of human $M Y H 9$ to that of mice in the genomic organisation suggests that the mouse is an excellent model to study the pathogenetic mechanisms responsible for human disease [22]. A homozygous NMHCIIA-knockdown mouse model demonstrated development of tongue SCC [23]. SCC occurred very early during embryonic epithelium development, with a $100 \%$ penetrance. Similar to the aforementioned cell line studies, oncogenesis in this mouse model was independent of defective p53 activation. From a protein perspective, Schramek et al. (2014) found that 24 and $31 \%$ of human skin and head and neck SCCs respectively were characterised by negligible or weak NMHCIIA immunohistochemical expression [13]. There is therefore accumulating evidence that MYH9 and its expression at both RNA and protein levels might play an important role in HNSCC.

\section{Case presentation}

A 19-year-old non-smoker female patient with $M Y H 9$ mutation (missense variant in exon 2: c.287C > T, (p.Ser96Leu)) was referred to our department for investigation of a painful, thick right tongue ulcer with reactive lymphadenitis. She had been diagnosed with oral thrush but had not responded to antifungal therapy. Her symptoms had persisted for some months. Her assessment was compromised by the unavailability of face to face consultation with her general practitioner during the early days of the Covid-19 pandemic.

She was diagnosed with Epstein syndrome at 12 years of age with severe thrombocytopenia (baseline count $5 \times 10^{9} / \mathrm{L}$ ), nephrotic syndrome with proteinuria (creatinine 298 with eGFR 19), and sensorineural deafness. When she was 18 months old, she was referred to a tertiary paediatric hospital by a local paediatrician for a sudden onset of bruising and a platelet count of $13 \times$ $10^{9} / \mathrm{L}$. The giant platelets were seen on blood films. Her parents both had normal platelet counts and blood films. The only family history was her maternal great-aunt, who died of leukaemia at 40 years of age. She was commenced on treatment for acute idiopathic 
thrombocytopenic purpura (ITP). A bone marrow aspirate and trephine were performed when she turned 7 years old. The trephine showed a normocellular marrow with increased megakaryocytes consistent with peripheral destruction. Cytogenetics confirmed a 46XX karyotype. She developed a life-threatening epistaxis when she was 8 years old, for which she was resuscitated with a pack red cell and platelet transfusion. She received intravenous immunoglobulin (IVIG) then, which was complicated by aseptic meningitis. Her platelet count rose from 1 to $87 \times 10^{9} / \mathrm{L}$, which was likely due to the platelet transfusion rather than the IVIG. She remained well until she was 12 years old when she had profound menorrhagia with haemoglobin $(\mathrm{Hb})$ of $55 \mathrm{~g} / \mathrm{L}$ and platelets of $4 \times 10^{9} / \mathrm{L}$. again she was administered blood product replacement as well as commenced on medroxyprogesterone and prednisolone $4 \mathrm{mg} / \mathrm{kg} /$ day for the provisional diagnosis of chronic ITP. The maximal platelet count during this admission was 38 . This was likely due to transfusion rather than prednisolone. Following this episode, she participated in the multi-centre international randomized controlled trial of romiplostim versus placebo in children with chronic ITP (Amgen study 20,080,279). Pre-trial screening incidentally revealed $3+$ proteinuria. Her serum albumin, creatinine and blood pressure were all normal. Her DNA was sent to Bristol Genetics Laboratory for steroid-resistant nephrotic syndrome gene panel testing. Analysis of the MYH9 gene revealed a pathogenic heterozygous missense mutation in exon 2, c.287C $>\mathrm{T}$, (p.Ser96Leu), which confirmed the diagnosis of MYH9-RD (Fig. 1). Her phenotype was that of autosomal dominant Epstein Syndrome.

Once the diagnosis of MYH9 related disorder diagnosis was confirmed, she withdrew from the trial. Later it was notified that she was receiving romiplostim, not a placebo. Since she was 18 months old, the highest recorded platelet count was $86 \times 10^{9} / \mathrm{L}$ when she received six weeks of $2 \mathrm{mg} / \mathrm{kg} /$ day prednisolone and was up to 9 $\mathrm{mcg} / \mathrm{kg} / \mathrm{dose}$ per week of romiplostim concurrently.

At initial surgical consultation, the patient reported a non-healing, painful, tongue ulcer unrelated to any trauma. She noticed the ulcer eight months prior, but unfortunately, the presentation was delayed due to COVID-19 and its surrounding safety measures. By the time of presentation, the ulcer has grown to $4 \mathrm{~cm}$ in size (Image 1).

Point of care ultrasound revealed lymphadenopathy. The working provisional clinical diagnosis was SCC. Tissue biopsy required preoperative platelet transfusion. The biopsy confirmed SCC in the primary site, but no malignancy was found in the palpable ipsilateral neck lymph nodes. Computed tomography (CT)/FDG PET showed suspicious avidity in the right tongue and $2 \mathrm{~A}$ cervical node (Image 2).

Following extensive multidisciplinary consultation and planning, she underwent surgery which comprised

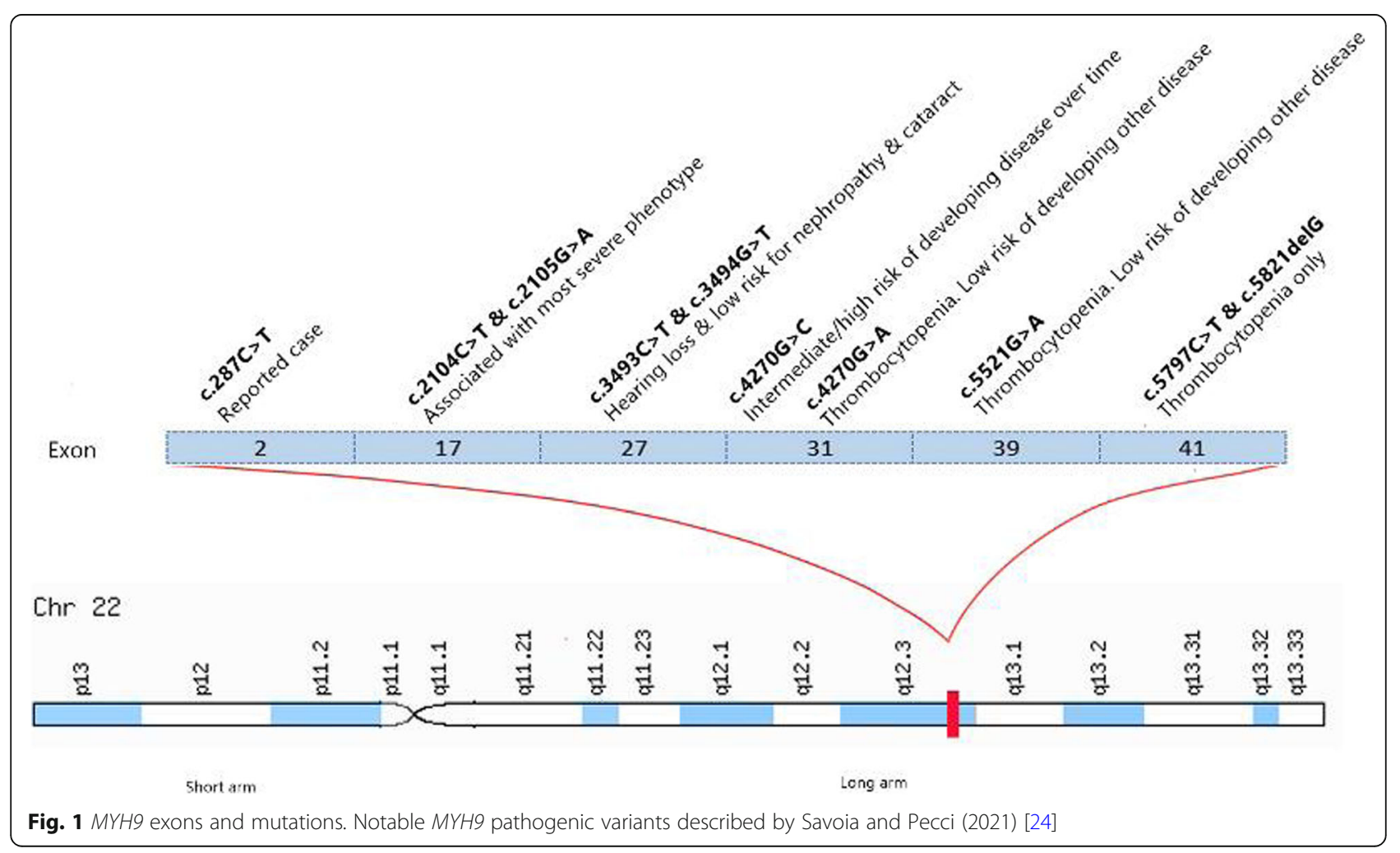




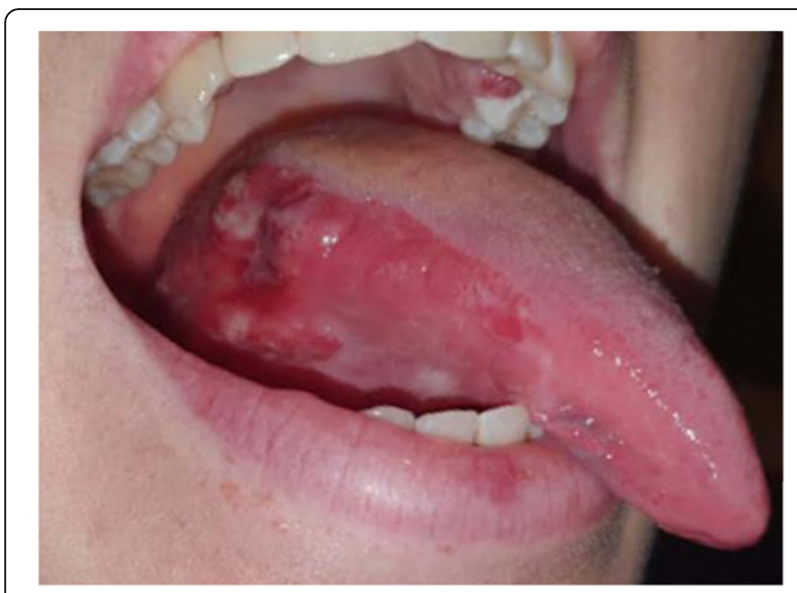

Image 1 Clinical photograph of right tongue lesion at presentation shows an ulcerated tumour with surrounding oedema and erythroplakia. Inflammatory/haemorrhagic lesion on the palatal aspect of left maxillary premolar was also noted

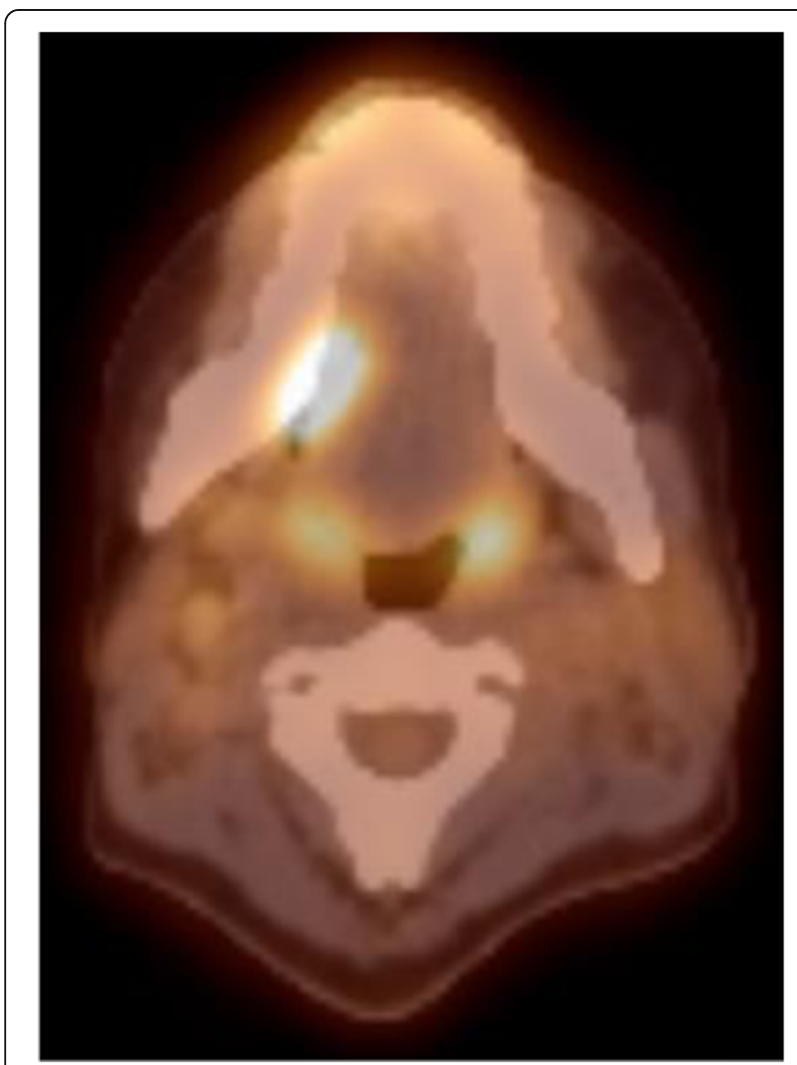

Image 2 Pre-operative PET/CT demonstrating 2,3

fluorodeoxyglucose avidity in the right tongue tumour. Mild lymph node avidity was also demonstrated but no evidence of distant PET avid disease tracheostomy, right hemiglossectomy, third molar tooth extraction, bilateral neck dissection (right level 1-4, left level 1-3), and radial forearm free flap reconstruction with microvascular anastomosis. Radial forearm free flap with 4 by $6 \mathrm{~cm}$ fasciocutaneous paddle was harvested with a vascular pedicle consisting of the radial artery, venae commitantes, and the cephalic vein. They were anastomosed to superior thyroid artery, internal jugular vein and common facial vein, respectively. Vessel diameters were between 2 and $4 \mathrm{~mm}$. Polyglactin 910 (Vicryl ${ }^{\mathrm{m}}$; Ethicon) 3-0 suture was used for the inset of the free flap to intraoral defect, and Vicryl ${ }^{\text {tw }} 3-0$ and poliglecaprone (Monocryl ${ }^{\mathrm{m}}$; Ethicon) 4-0 sutures were used for skin closure. She received 2 HLA matched pool platelets perioperatively aiming for the count above $50 \times 10^{9} / \mathrm{L}$. One unit of packed red cell and $2 \mathrm{~g}$ of tranexamic acid were administered intraoperatively. The surgical procedure was completed with a total operative time of $6 \mathrm{~h} 42$ min with an ischaemic time of $1 \mathrm{~h} 20 \mathrm{~min}$ for the free flap harvest. The tourniquet time was $58 \mathrm{~min}$. The estimated total blood loss was $200 \mathrm{~mL}$. The platelet count was $69 \times 10^{9} / \mathrm{L}$, and $\mathrm{Hb}$ was $94 \mathrm{~g} / \mathrm{L}$ at the completion of the case. She received routine postoperative orders, including monitoring in the high dependency unit (HDU), hourly flap observations, $48 \mathrm{~h}$ of intravenous (IV) antibiotics (cephazolin $1 \mathrm{~g}$ three times per day and metronidazole $500 \mathrm{mg}$ twice per day), nasogastric feeding, but no chemical venous thromboembolism (VTE) prophylaxis. She had an uneventful recovery including the removal of her tracheostomy on day 4 and was discharged home on day 6 postoperative day on a soft diet.

On day 15, she was assessed by the speech and language pathologist. Part of this assessment was a modified barium swallow study. During this test she had a coughing paroxysm. This precipitated neck swelling and airway embarrassment. She was transported to the Emergency Department for urgent assessment. Due to impending respiratory arrest, an emergency airway was established via the existing tracheostomy site which had not fully healed and the patient was then transferred to theatre for neck exploration and control of haemorrhage. Bleeding was found from the free flap pedicle vessels. After two days of intensive care unit (ICU) then surgical ward stay, she was discharged home with surgical and radiation oncology follow up.

Her pathology demonstrated a moderately differentiated SCC of the oral tongue with a maximum dimension of $35 \mathrm{~mm}$ and up to $14 \mathrm{~mm}$ thick. The tumour had an endophytic growth pattern, and multiple foci of lymphovascular invasion (LVI) and perineural invasion (PNI) were seen. Margins were clear. Two (level IB and IIA) out of 38 right neck nodes contained metastatic SCC, measuring $22 \mathrm{~mm}$, and both had a focal extranodal extension of $1 \mathrm{~mm}$ (Image 3). None of the 34 lymph nodes 




Image 3 Histological slides a SCC (H\&E $\times 100)$ at surface of tumour demonstrating irregular nests of highly atypical squamous cells invading the submucosal space, with adjacent oral mucosa at top left; b SCC (H\&E $\times 100)$, present as infiltrative tumoural nests with keratinisation, at invasive front of tumour; $\mathbf{c}$ Lymph node metastasis $(H \& E \times 20)$ demonstrating extranodal extension of SCC in to adjacent soft tissue

from the left neck was involved. Her pathological tumour stage was Stage 4 (pT3, pN3b), according to the American Joint Committee on Cancer (AJCC) 8th edition.

She had clear indications for adjuvant chemoradiotherapy, including nodal involvement, extracapsular extension and multifocal LVI and PNI. She received adjuvant radiotherapy but, despite disease indications, was unable to receive chemotherapy due to her renal impairment.

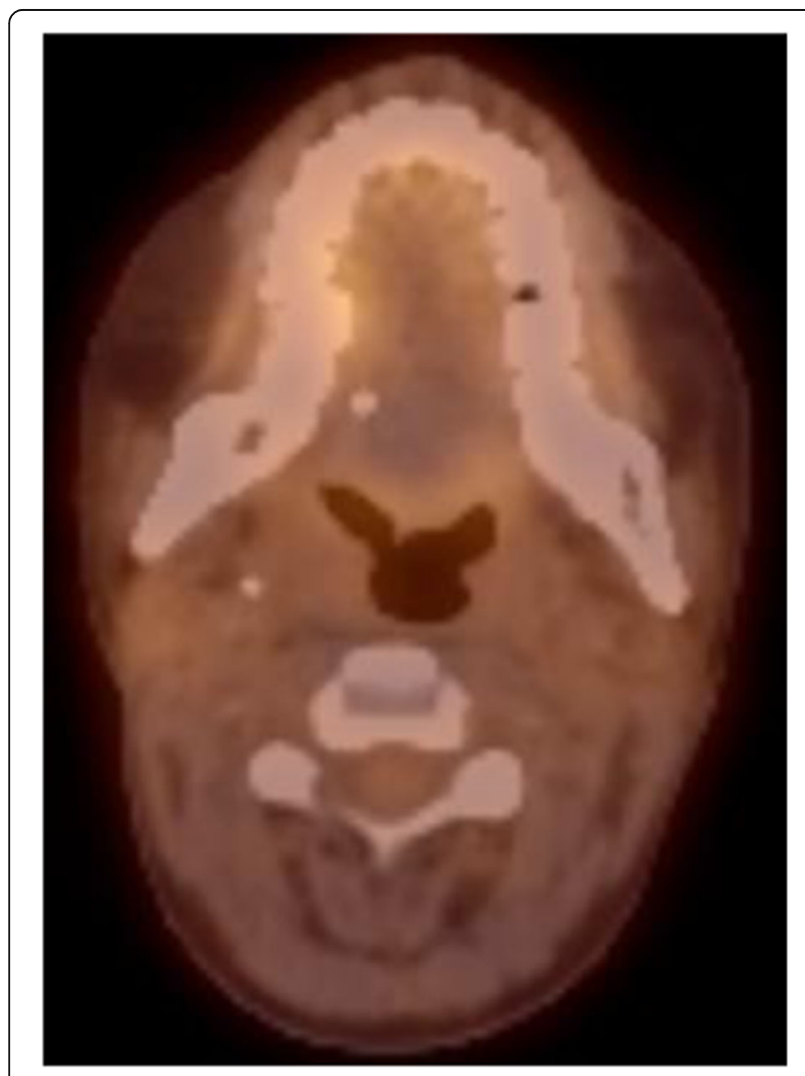

Image 4 Post-operative PET/CT at 6 months showing mild persistent avidity in the right tongue in keeping with local trauma to the flap reconstruction
She received 60Gy RT in 30 fractions. On clinical examination and PET at 6 months after surgery she had no evidence of disease recurrence (Image 4).

\section{Discussion and conclusions}

Tongue cancers in young adults, let alone teenagers, are relatively uncommon compared to the older individuals. Time to diagnosis may also be longer because healthcare professionals may not have thought about malignancy as differential diagnosis. Retrospective analysis of adolescent and young adult generation with oral cancer by Yoshioka et al. [25] demonstrated that tongue was the most common subsite and SCC was the most common histological type. The role of MYH9 in oSCC in humans has not been described before, however, various studies have shown in vitro tumorigenic properties of MYH9 variation [26-29]. The role of MYH9 in cancer is context dependent and can act both as a tumour promoter and suppressor in different cancers. The role of $M Y H 9$ as a tumour suppressor has been proposed in murine models of head and neck cancer, where loss of $M Y H 9$ results in the development of SCC and increased cell invasion $[15,23]$. In the reported case, the combination of genetic predisposition and immunosuppression by renal failure further increases the risk of HNSCC. Murayama et al. (2013) reported a case of 1 year old boy and 33 year old father who shared the same genetic mutation as the reported case [30]. Their clinical course was similar to the case presented except neither developed documented malignancy.

The observation of an affected family pedigree described in the paper by Althaus (2010) demonstrated the following; 1) bleeding is usually not the leading problem in many of these patients 2) in patients with a history of only minor bleeding, prophylactic platelet transfusion before the major surgery is not necessary 3 ) pregnancy is usually not complicated by significant bleeding and spontaneous delivery seems to be appropriate without risk of intracerebral bleeding as newborns 4) $\mathrm{MYH}-9$ 
related thrombocytopenia does not protect from a thromboembolic event such as myocardial infarction (MI). Around $28 \%$ of patients present spontaneous mucosal bleeding, mainly menorrhagia, epistaxis, and gum bleeding, but life-threatening haemorrhages are rare [31]. In the presented case, she had life-threatening haemorrhages since her childhood and required perioperative platelet transfusion prophylactically.

A low haematocrit will exacerbate the impaired platelet subendothelial interactions even with normal platelets [32]. The thrombopoietin receptor agonist Eltrombopag has been used successfully for preparing patients with severe MYH9-related thrombocytopenia for elective surgery [33-35]. Romiplostim, another agonist of the thrombopoietin receptor, was also used for this purpose in one MYH9-RD patient [36]. Thrombopoietin receptor agonists increase the production of even larger platelets because the fragmentation defect is still present. These giant platelets are larger than the capillaries' diameter, and increasing the number of giant platelets may worsen the microcirculation [6]. Therefore, thrombopoietin receptor agonist could be considered as an adjunct to major surgery, however, its effect on microcirculation needs to be carefully considered in free flap reconstructions.

The aims of cancer care are histological confirmation of diagnosis, staging of disease and definitive treatment. Each step of the management in this case was impacted by the underlying bleeding tendency and renal failure. For diagnosis of oSCC, a punch or incisional biopsy is required. In the case of palpable cervical lymphadenopathy, cytological assessment by ultrasound guided FNA is also indicated. These procedures can usually be performed as an outpatient under local anaesthesia. However, in this case, the patient required preoperative platelet transfusion, general anaesthesia and overnight inpatient observation to safely manage the risk of airway obstruction due to bleeding. Standard staging protocol for oSCC includes CT head and neck, or magnetic resonance imaging (MRI), and PET scan. The purpose of imaging is to assess local staging and distant disease. The presence of distant disease precludes the patient from having a curative surgery. The imaging enhancing contrast may be nephrotoxic [37]. Renal protective measures such as intravenous (IV) fluid and $\mathrm{N}$-acetylcysteine may be required.

Standard therapy for locally advanced lateral tongue SCC is partial glossectomy, selective neck dissection and reconstruction. This patient underwent bilateral instead of ipsilateral neck dissection as the tumour was clinically thick, and there was a clinical concern for bilateral disease. Tracheostomy was created for airway protection in case of large haematoma or life-threatening haemorrhage. Tracheostomy is not routinely performed for the size and location of her resection. She was decannulated on day 2 postoperative day. Reconstruction using free tissue transfer is routine following hemiglossectomy in order to achieve acceptable tongue function, swallowing and speech.

The use and type of postoperative anticoagulation is institution dependent. At least two patients with MYH9RDs are reported to have developed thrombosis following surgery $[38,39]$. Therefore venous thromboembolic prophylaxis should be considered in situations with a high risk of thrombosis. It is crucial if antifibrinolytic agents are given to prevent bleeding during the surgery. The application, indications, timing, and duration are currently based on personal experience and practice [40]. However, most institutions use subcutaneous heparin or low molecular weight heparin (LMWH). Because vascular autonomic regulation is often impaired by the flap harvest significantly higher perfusion values can be observed at the time of subsequent reperfusion [41]. Heat-induced vasodilatation, which requires intact innervation (mostly mediated by c-afferents) and endothelial function, is also lost in the free flaps [42, 43]. Surgical manipulation of the endothelium and the trauma often leads to anastomotic complications due to the sub-intimal collagen exposure; moreover, it triggers coagulation and microthrombi formation [44]. Hypercoagulability, venous stasis, and endothelial injury, known as Virchow's triad, are all encountered during free flaps surgery [45]. It is uncertain if the presence of giant platelets compromises microcirculation within free flaps due to altered viscosity. Preoperative chemical VTE prophylaxis was omitted in our patient while mechanical VTE prophylaxis, including thromboembolic deterrent stocking (TEDS) and intermittent pneumatic compression (IPC), were applied. The decision was based on the assumption that she would have lower risk of VTE.

When this patient was taken back to theatre for lifethreatening bleeding after a forceful coughing during swallow assessment, the feeding vascular pedicle was ligated. The free flap survived despite early loss of feeding vessels. There is no data available for tissue healing in the setting of $M Y H 9$ mutation.

The platelet count was $8 \times 10^{9} / \mathrm{L}$ on the modified barium swallow test. The blood count is not routinely checked before postoperative functional studies. We suggest to include routine haematological examination before post-operative swallowing assessments. As described in our case, a forceful coughing during routine swallow test induced life-threatening haemorrhage and respiratory arrest. Peri-assessment platelet transfusion may be necessary at discretion of treating haematologist.

Typically, in the setting of extranodal extension of SCC, combination chemoradiation with cisplatin is indicated to improve regional control. However 
chemotherapy was omitted in this case due to the preexisting thrombocytopenia, impaired renal function and impaired hearing. All patients undergoing head and neck radiation treatment develop confluent mucosal ulcers as well as skin desquamation. Basic supportive measures are generally sufficient, but these ulcers may bleed significantly in this patient's situation, and such problems can persist for several weeks. To prevent catastrophic bleeding during radiotherapy treatment, she needed to receive regular platelet transfusion during the second half of the treatment regime and 3 to 4 weeks posttreatment.

This patient had extensive ablative and reconstructive surgery as she presented with locally advanced disease. If the primary disease were detected early, it would have been possible to manage it with a less invasive and less morbid procedure such as laser excision. It emphasises the importance of education to the patient, family and treating clinicians to have a low threshold to investigate suspicious idiopathic lesions.

The usual time frame for head and neck cancer surveillance is five years. There is no reliable data on risk of second primary oral cavity malignancy, and so surveillance may need to be prolonged.

We report a 19 year old female patient with Epstein syndrome with a locally advanced tongue SCC who underwent extensive ablative and reconstructive surgery. This is the first case of oral tongue SCC in the context of MYH9-RD. Complex multidisciplinary consultation and planning were the cornerstones of safe patient care. The importance of cancer awareness and early detection in MYH9-RD is emphasised and oral cavity SCC in these diseases requires further characterisation.

\section{Abbreviations \\ CT: computerised tomography; FDG/PET: Fluorodeoxyglucose/positron emission tomography; FNA: fine needle aspirate; HB: haemoglobin; HLA: human leukocyte antigen; ICU: intensive care unit; IPC: intermittent pneumatic compression; ITP: thrombocytopenic purpura; IVIG: intravenous immunoglobulin; LMWH: low molecular weight heparin; LVI: lymphovascular invasion; MRI: magnetic resonance imaging; MUT: mutated; MYH9: Myosin Heavy Chain 9; NMHCIIA: non-muscular myosin heavy chain IIA; OSCC: oral squamous cell carcinoma; PNI: perineural invasion; TEDS: thromboembolic deterrent stocking; VTE: venous thromboembolism; WT: wild type}

\section{Acknowledgments}

Not applicable.

\footnotetext{
Authors' contributions

TY contributed to the patient care, drafted, revised and edited the manuscript. KK contributed to the patient care and reviewed the manuscript. SR contributed to the patient care and reviewed the manuscript. LS performed the histological examination of the surgical specimen and reviewed the manuscript. RG performed the histological examination of the surgical specimen and reviewed the manuscript. JC contributed to the patient care and reviewed the manuscript. BA was the principal treating surgeon and contributed to the conception of the manuscript and revised the manuscript. All authors read and approved the final manuscript.
}

\section{Funding}

The authors declare that they did not receive any funding for the production of this manuscript

\section{Availability of data and materials}

Data sharing is not applicable to this article as no datasets were generated or analysed during the current study. Not applicable.

\section{Declarations}

Ethics approval and consent to participate

Not applicable.

\section{Consent for publication}

Informed consent for publication was obtained and is available for review by the editor.

\section{Competing interests}

The authors declare that they have no completing interests.

\section{Author details}

${ }^{1}$ Department of Head and Neck Surgery, Wollongong Hospital, Wollongong, NSW, Australia. ${ }^{2}$ Illawarra Health and Medical Research Institute, Wollongong, NSW, Australia. ${ }^{3}$ Illawarra Shoalhaven Local Health District, NSW Health Pathology South, Wollongong Hospital, Wollongong, NSW, Australia. ${ }^{4}$ Kids Cancer Centre, Sydney Children's Hospital, Sydney, NSW, Australia. ${ }^{5}$ School of Women's and Children's Health, University of New South Wales Sydney, Sydney, NSW, Australia. ${ }^{6}$ Department of Tissue Pathology and Diagnostic Oncology, Royal Prince Alfred Hospital, Sydney, NSW, Australia. ${ }^{7}$ Central Clinical School, The University of Sydney, Sydney, NSW, Australia.

${ }^{8}$ Department of Radiation Oncology, Wollongong Hospital, Wollongong, NSW, Australia. ${ }^{9}$ Faculty of Science, Medicine and Health, University of Wollongong, Wollongong, NSW, Australia.

Received: 14 October 2021 Accepted: 25 January 2022

Published online: 06 February 2022

\section{References}

1. Satgunaseelan L, Allanson BM, Asher R, Reddy R, Low HTH, Veness M, et al. The incidence of squamous cell carcinoma of the oral tongue is rising in young non-smoking women: An international multi-institutional analysis. Oral Oncol. 2020;110:104875.

2. Furquim CP, Pivovar A, Amenábar JM, Bonfim C, Torres-Pereira CC. Oral cancer in Fanconi anemia: review of 121 cases. Crit Rev Oncol Hematol. 2018;125:35-40. https://doi.org/10.1016/j.critrevonc.2018.02.013.

3. Alter BP, Giri N, Savage SA, Rosenberg PS. Cancer in dyskeratosis congenita. Blood. 2009:113(26):6549-57. https://doi.org/10.1182/blood-2008-12-192880.

4. Vicente-Manzanares M, Ma X, Adelstein RS, Horwitz AR. Non-muscle myosin Il takes Centre stage in cell adhesion and migration. Nat Rev Mol Cell Biol. 2009;10(11):778-90. https://doi.org/10.1038/nrm2786

5. Kunishima S, Saito $\mathrm{H}$. Advances in the understanding of MYH9 disorders. Curr Opin Hematol. 2010;17(5):405-10. https://doi.org/10.1097/MOH.0b013 e32833c069c.

6. Althaus K, Greinacher A. MYH-9 related platelet disorders: strategies for management and diagnosis. Transfus Med Hemother. 2010;37(5):260-7. https://doi.org/10.1159/000320335

7. Fernandez-Prado R, Carriazo-Julio SM, Torra R, Ortiz A, Perez-Gomez MV. MYH9-related disease: it does exist, may be more frequent than you think and requires specific therapy. Clin Kidney J. 2019;12(4):488-93. https://doi. org/10.1093/ckj/sfz103

8. Seri M, Pecci A, Di Bari F, Cusano R, Savino M, Panza E, et al. MYH9-related disease: may-Hegglin anomaly, Sebastian syndrome, Fechtner syndrome, and Epstein syndrome are not distinct entities but represent a variable expression of a single illness. Medicine. 2003;82(3):203-15. https://doi.org/1 0.1097/01.md.0000076006.64510.5c.

9. Savoia A, De Rocco D, Panza E, Bozzi V, Scandellari R, Loffredo G, et al. Heavy chain myosin 9-related disease (MYH9-RD): neutrophil inclusions of myosin-9 as a pathognomonic sign of the disorder. Thromb Haemost. 2010; 103(04):826-32. https://doi.org/10.1160/TH09-08-0593.

10. Savoia A, Pecci A. MYH9-related disorders. 2015. 
11. Betapudi V, Licate LS, Egelhoff $\Pi$. Distinct roles of nonmuscle myosin II isoforms in the regulation of MDA-MB-231 breast cancer cell spreading and migration. Cancer Res. 2006;66(9):4725-33. https://doi.org/10.1158/0008-54 72.CAN-05-4236.

12. Katono K, Sato $Y$, Jiang $S-X$, Kobayashi M, Nagashio R, Ryuge $S$, et al. Prognostic significance of MYH9 expression in resected non-small cell lung cancer. PLoS One. 2015;10(3):e0121460. https://doi.org/10.1371/journal.pone. 0121460.

13. Schramek D, Sendoel A, Segal JP, Beronja S, Heller E, Oristian D, et al. Direct in vivo RNAi screen unveils myosin lla as a tumor suppressor of squamous cell carcinomas. Science. 2014;343(6168):309-13. https://doi.org/10.1126/ science.1248627.

14. Xia Z, Yuan Y, Yin N, Yin B, Tan Z, Hu Y. Nonmuscle myosin IIA is associated with poor prognosis of esophageal squamous cancer. Dis Esophagus. 2012; 25(5):427-36. https://doi.org/10.1111/j.1442-2050.2011.01261.x.

15. Coaxum SD, Tiedeken J, Garrett-Mayer E, Myers J, Rosenzweig SA, Neskey DM. The tumor suppressor capability of p53 is dependent on non-muscle myosin IIA function in head and neck cancer. Oncotarget. 2017:8(14):229913007. https://doi.org/10.18632/oncotarget.14967.

16. Network CGA. Comprehensive genomic characterization of head and neck squamous cell carcinomas. Nature. 2015;517(7536):576-82. https://doi.org/1 0.1038 /nature14129.

17. Agrawal N, Frederick MJ, Pickering CR, Bettegowda C, Chang K, Li RJ, et al. Exome sequencing of head and neck squamous cell carcinoma reveals inactivating mutations in NOTCH1. Science. 2011;333(6046):1154-7. https:// doi.org/10.1126/science.1206923.

18. Stransky N, Egloff AM, Tward AD, Kostic AD, Cibulskis K, Sivachenko A, et al. The mutational landscape of head and neck squamous cell carcinoma. Science. 2011;333(6046):1157-60. https://doi.org/10.1126/science.1208130.

19. Sandquist JC, Swenson Kl, DeMali KA, Burridge K, Means AR. Rho kinase differentially regulates phosphorylation of nonmuscle myosin II isoforms a and B during cell rounding and migration. J Biol Chem. 2006;281(47):3587383. https://doi.org/10.1074/jbc.M605343200.

20. Even-Ram S, Doyle AD, Conti MA, Matsumoto K, Adelstein RS, Yamada KM Myosin IIA regulates cell motility and actomyosin-microtubule crosstalk. Nat Cell Biol. 2007;9(3):299-309. https://doi.org/10.1038/ncb1540.

21. Petrie RJ, Koo H, Yamada KM. Generation of compartmentalized pressure by a nuclear piston governs cell motility in a 3D matrix. Science. 2014; 345(6200):1062-5. https://doi.org/10.1126/science.1256965.

22. Pecci A, Ma X, Savoia A, Adelstein RS. MYH9: structure, functions and role of non-muscle myosin IIA in human disease. Gene. 2018;664:152-67. https:// doi.org/10.1016/j.gene.2018.04.048.

23. Conti MA, Saleh AD, Brinster LR, Cheng H, Chen Z, Cornelius S, et al. Conditional deletion of nonmuscle myosin $\|-A$ in mouse tongue epithelium results in squamous cell carcinoma. Sci Rep. 2015;5(1):1-11.

24. Savoia A, Pecci A. MYH9-related disease. In: GeneReviews ${ }^{\oplus}[$ Internet]. Seattle: University of Washington; 2021.

25. Yoshioka Y, Sakaue T, Matsui K, Tsushima K, Obayashi F, Hamada A, et al Clinical investigation of oral cancer in adolescent and young adult generation. In: Oral Science International. 2021

26. Shin D-H, Kim O-H, Jun H-S, Kang M-K. Inhibitory effect of capsaicin on B16F10 melanoma cell migration via the phosphatidylinositol 3-kinase/Akt/Rac1 signal pathway. Exp Mol Med. 2008;40(5):486-94. https://doi.org/10.3858/ emm.2008.40.5.486.

27. Zhao K, Wei L, Hui H, Dai Q, You Q-D, Guo Q-L, et al. Wogonin suppresses melanoma cell B16-F10 invasion and migration by inhibiting Ras-medicated pathways. PLoS One. 2014;9(9):e106458. https://doi.org/10.1371/journal. pone.0106458

28. Koszałka P, Pryszlak A, Gołuńska M, Kolasa J, Stasiłojć G, Składanowski AC, et al. Inhibition of CD73 stimulates the migration and invasion of B16F10 melanoma cells in vitro, but results in impaired angiogenesis and reduced melanoma growth in vivo. Oncol Rep. 2014;31(2):819-27. https://doi.org/1 0.3892/or.2013.2883

29. Abd Razak N, Abu N, Ho WY, Zamberi NR, Tan SW, Alitheen NB, et al. Cytotoxicity of eupatorin in MCF-7 and MDA-MB-231 human breast cancer cells via cell cycle arrest, anti-angiogenesis and induction of apoptosis. Sci Rep. 2019;9(1):1-12.

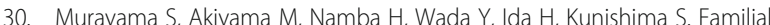
cases with MYH9 disorders caused by MYH9 S96L mutation. Pediatr Int. 2013;55(1):102-4. https://doi.org/10.1111/j.1442-200X.2012.03619.x.
31. Pecci A, Klersy C, Gresele P, Lee KJ, De Rocco D, Bozzi V, et al. MYH 9-related disease: a novel prognostic model to predict the clinical evolution of the disease based on genotype-phenotype correlations. Hum Mutat. 2014;35(2): 236-47. https://doi.org/10.1002/humu.22476.

32. Eugster $\mathrm{M}$, Reinhart $\mathrm{WH}$. The influence of the haematocrit on primary haemostasis in vitro. Thromb Haemost. 2005;94(12):1213-8. https://doi.org/1 0.1160/TH05-06-0424.

33. Pecci A, Barozzi S, d'Amico S, Balduini CL. Short-term eltrombopag for surgical preparation of a patient with inherited thrombocytopenia deriving from MYH9 mutation. Thromb Haemost. 2012;107(06):1188-9. https://doi. org/10.1160/TH12-01-0005

34. Favier R, Feriel J, Favier M, Denoyelle F, Martignetti JA. First successful use of eltrombopag before surgery in a child with MYH9-related thrombocytopenia. Pediatrics. 2013;132(3):e793-5. https://doi.org/10.1542/ peds.2012-3807.

35. Favier R, De Carne C, Elefant E, Lapusneanu R, Gkalea V, Rigouzzo A. Eltrombopag to treat thrombocytopenia during last month of pregnancy in a woman with MYH9-related disease: a case report. A A Pract. 2018;10(1): 10-2. https://doi.org/10.1213/XAA.0000000000000621.

36. Yamanouchi J, Hato T, Kunishima S, Niiya T, Nakamura H, Yasukawa M. A novel MYH9 mutation in a patient with MYH9 disorders and platelet sizespecific effect of romiplostim on macrothrombocytopenia. Ann Hematol. 2015;94(9):1599-600. https://doi.org/10.1007/s00277-015-2416-x.

37. Ozkok S, Ozkok A. Contrast-induced acute kidney injury: a review of practical points. World J Nephrol. 2017;6(3):86-99. https://doi.org/10.5527/ wjn.v6.i3.86.

38. Heller PG, Pecci A, Glembotsky AC, Savoia A, Negro FD, Balduini CL, et al. Unexplained recurrent venous thrombosis in a patient with MYH 9-related disease. Platelets. 2006;17(4):274-5. https://doi.org/10.1080/174769305004 67235.

39. Selleng K, Lubenow LE, Greinacher A, Warkentin TE. Perioperative management of MYH9 hereditary macrothrombocytopenia (Fechtner syndrome). Eur J Haematol. 2007;79(3):263-8. https://doi.org/10.1111/j.16000609.2007.00913.x

40. Gravvanis Al, Tsoutsos DA, Lykoudis EG, Iconomou TG, Tzivaridou DV, Papalois $A E$, et al. Microvascular repair following crush-avulsion type injury with vein grafts: effect of direct inhibitors of thrombin on patency rate. Microsurgery. 2003;23(4):402-7. https://doi.org/10.1002/micr.10146.

41. Landsverk SA, Kvandal P, Kjelstrup T, Benko U, Bernjak A, Stefanovska A, et al. Human skin microcirculation after brachial plexus block evaluated by wavelet transform of the laser Doppler flowmetry signal. Anesthesiology. 2006;105(3):478-84. https://doi.org/10.1097/00000542-200609000-00010.

42. Rossi M, Carpi A, Galetta F, Franzoni F, Santoro G. The investigation of skin blood flowmotion: a new approach to study the microcirculatory impairment in vascular diseases? Biomed Pharmacother. 2006;60(8):437-42. https://doi.org/10.1016/j.biopha.2006.07.012.

43. László I, Janovszky Á, Lovas A, Vargán V, Öveges N, Tánczos T, et al. Effects of goal-directed crystalloid vs. colloid fluid therapy on microcirculation during free flap surgery: a randomised clinical trial. Eur J Anaesthesiol. 2019; 36(8):592-604. https://doi.org/10.1097/EJA.0000000000001024.

44. Kaciulyte J, Losco L, Maruccia M, Delia G, TORTO F, Di Taranto G, et al. Postsurgical antithrombotic therapy in microsurgery: our protocol and literature. Eur Rev Med Pharmacol Sci. 2019:23:4448-57.

45. Lecoq J-P, Senard M, Hartstein G, Lamy M, Heymans O. Thromboprophylaxis in microsurgery. Acta Chir Belg. 2006;106(2):158-64. https://doi.org/10.1080/ 00015458.2006 .11679863

\section{Publisher's Note}

Springer Nature remains neutral with regard to jurisdictional claims in published maps and institutional affiliations. 